\title{
White Pine BLister Rust in the Greater Yellowstone Area
}

\author{
MARIA NEWCOMB $\uparrow$ DIANA SIX \\ CONSULTATION BY CAROL BREWER \\ DIVISION OF BIOLOGY \\ UNIVERSITY OF MONTANA $\downarrow$ MISSOULA
}

\section{$\downarrow$ INTRODUCTION}

White pine blister rust is a disease caused by an introduced fungal pathogen (Cronartium ribicola). The disease system is a complex cross-Kingdom interaction between three groups of organisms (white pines, Ribes, and a fungal pathogen). The pathogen alternates between white pine hosts (subgenus Strobus) where it persists as a perennial and often lethal infection, and currant and gooseberry hosts (members of the genus Ribes) where it infects the deciduous leaves and results in relatively minor impacts. In many areas of North America white pines are severely threatened by the disease, which is often recognized as the most devastating disease of conifers (Klinkowski 1970). Since the early 1900s when the pathogen first arrived in North America, forest managers have been challenged by the difficulties of blister rust control and predictions of damage and spread. Recent control efforts have focused on developing rust-resistant white pines (Maloy 1997). Advances in molecular techniques have led to a rapid increase in our understanding of pathogen virulence and plant disease resistance. Thus thorough research on white pine blister rust will encompass a combination of investigations of small parts of the system, including molecular descriptions of individual members and controlled-environment studies of simplified interactions, and ecological investigations of infection patterns in real-world forest conditions (where all the parts are interacting simultaneously). This study is a field investigation of white pine blister rust in the Greater Yellowstone Area (GYA).
Two white pine species occur within the GYA: whitebark pine (Pinus albicaulis) and limber pine (Pinus flexilis). Whitebark pine inhabits more acreage than limber pine. It is a slow-growing, highelevation species that provides watershed protection, wildlife cover, and an important food source for birds, small mammals, and bears, including the federally protected grizzly bear. Numerous Ribes species inhabit the GYA, and seven species are listed in the Flora of Yellowstone National Park (Despain 1975). The host plants and their interactions with the fungal pathogen are strongly influenced by the climatic conditions and meteorological events of the GYA. Leaf-level moisture and temperature conditions that occur within host plant canopies can limit fungal spore germination and infection (Mielke 1943). Thus macro- and micro-climate conditions are important influences on disease spread and intensification. Frequent claims have been made that ecological conditions in the GYA generally limit the spread and intensification of the blister rust pathogen (Carlson 1978). However, it must be realized that pine infection can still become established through episodic events, even if infrequent.

White pine blister rust has been present in white pines of the GYA since the 1940s (Krebill 1969) and at present occurs in a patchy and variable distribution, with some sites highly infected and others barely infected. The fact that the pathogen has had a long-term presence in the area but still occurs in variable intensities provides a model study area for examining patterns of association between site factors and high and low infection levels. Two recent well-designed studies that have considered whitebark 
pine forests across particular regions (British Columbia and the Intermountain West) surveyed white pine blister rust disease levels in correlation to various climatic and site and stand variables (Campbell and Antos 2000, Smith and Hoffman 2001). Results from the two studies showed somewhat different trends, which may be accounted for by regional differences, but also by the fact that the complexity of forest landscapes and the variability in individual host/pathogen genotypic interactions can make trends in disease distributions difficult to discern. Thus, the objective of this study during 2001 was to focus on the epidemiology of white pine blister rust in whitebark pine within a more localized (thus more homogeneous) area, the GYA, to look for trends in pathogen distribution/intensity. An assessment of quantitative trends in diseases can lead to a better mechanistic understanding (Weiner 1995).

\section{$\uparrow \quad$ METHODS}

An epidemiological study of white pine blister rust must consider 1) the pathogen, 2) the pine hosts, 3) the Ribes hosts, and 4) environmental conditions.

The pathogen: Disease levels and host plant factors were measured in 17 whitebark pine stands throughout portions of the Gallatin, Bridger Teton, and Targhee National Forests, as well as Yellowstone and Grand Teton National Parks. Stands were selected, as much as possible, such that whitebark pine was the major tree species. Site selection was also based on covering a wide range of infection levels. At each stand, 28 trees were sampled for disease intensity estimations. Disease level was assessed using two methods. The first method required a simple count of all discernable cankers divided into categories of the upper, middle and lower thirds of the tree canopy. The second method gave a numerical rating, based on the percentage of visible infection in the foliage and on the bole (D.L. Six, C. Austin and K. Baker, unpublished).

Pine hosts: The following data were recorded for each sample tree that was assessed for infection: Diameter at $1.4 \mathrm{~m}$, estimated height, canopy position, and presence of cones or mountain pine beetle. A larger area surrounding the sample trees was used to measure whitebark pine density, spatial associations between whitebark trees and onsite Ribes, and percent tree canopy cover. Whitebark pine density was estimated using a wandering-quarter transect method (Catana 1963) oriented to remain within a fairly homogeneous forest stand. At each whitebark pine tree encountered along the wandering quarter transect, a distance was measured from the tree to the nearest Ribes shrub (if Ribes were present). A line transect was then established along the general midline of the wandering transect. At stratified random points along the line a tree canopy cover percentage measurement was taken (using a convex densiometer) and the distance from the point to the nearest Ribes shrub was measured.

Ribes hosts: Ribes species were present at fewer than half of the sites that were quantitatively characterized. When Ribes plants were present, a variable-area transect (Parker 1979) was established perpendicular to the line transect at every fourth stratified random point to estimate Ribes densities by species. The direction of the variable-area transect alternated between upslope and downslope directions. Total leaf area, which is related to plant volume, is the important factor for pathogen infection and inoculum potential. Measurements relating to plant volume were therefore recorded for Ribes encountered in the variable-area transect. Additionally, the overstory cover above the Ribes shrubs may be important for limiting spore dispersal from Ribes to whitebark pines. Thus densiometer readings were made at canopy-level over Ribes shrubs encountered in the transects.

Environmental conditions: Data-loggers for monitoring weather were deployed within the foliage of host plants (Ribes and pines) to record rainfall, relative humidity, air temperature, and estimated leaf wetness at 60 s intervals. Two tipping buckets were used to record timing and durations of rainfall events. Other weather-recording equipment was generally clustered around the tipping buckets. One set of equipment was positioned in the northern portion of the study area (on Palmer Mountain in the Gallatin National Forest) and one set south of that site in the Teton Range (Rendezvous Mountain in Grand Teton National Park).

\section{$\uparrow \quad$ RESULTS}

Sites that were quantitatively described encompassed a wide range of infection levels. Four sites showed no visible infection on the sample trees, although at all sites cankers were observed on trees in the general vicinity. Three sites showed relatively high infection levels, with an average number of cankers per tree greater than 7. (The average number of cankers per tree provides a more thorough 
description of infection level than the percentage of trees with infection.) Other sites showed intermediate levels of infection.

There were no discernable trends between average number of cankers and any measured site or stand characteristics. Site elevations ranged from 2700-3080m, with high and low infections occurring across elevations. The correlation coefficient for average number of cankers and whitebark pine density was -0.28 , and for average number of cankers and Ribes density it was +0.08 (Fig. 1).
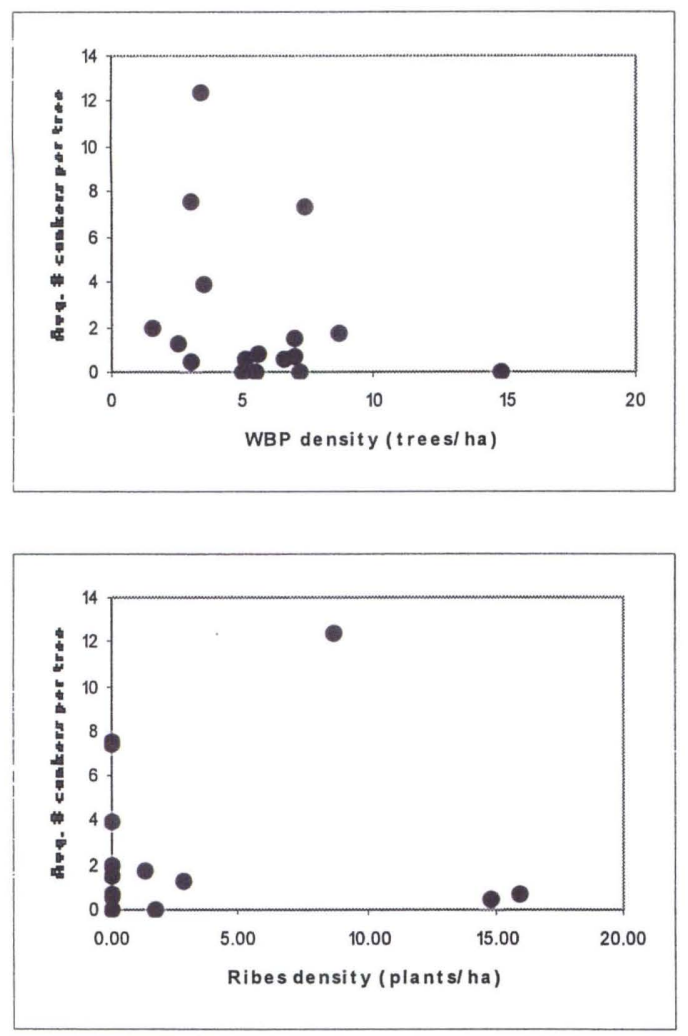

Figure 1. Relationship between host densities (whitebark pine and Ribes spp.) and average number of blister rust cankers per tree for 17 whitebark pine stands.

The average distribution of visible cankers throughout the tree canopy was not even. The mean number of cankers in the lower third of the tree canopies (across sites) was significantly less than the mean number in the middle $(\mathrm{p}=0.01)$ or upper $(p=0.03)$ thirds (Figure 2$)$. It is generally believed that spores dispersed over short-distances will be trapped by lower portions of the tree canopy than spores dispersed over longer-distances that travel by wind and can be transported upward as the spore plume expands outward (McCartney 1994). The observed trend for cankers to be less numerous in the lower portion of the canopy could represent a tendency for long-distance spore dispersal to be more common than short-distance dispersal in these upperelevation whitebark pine stands.

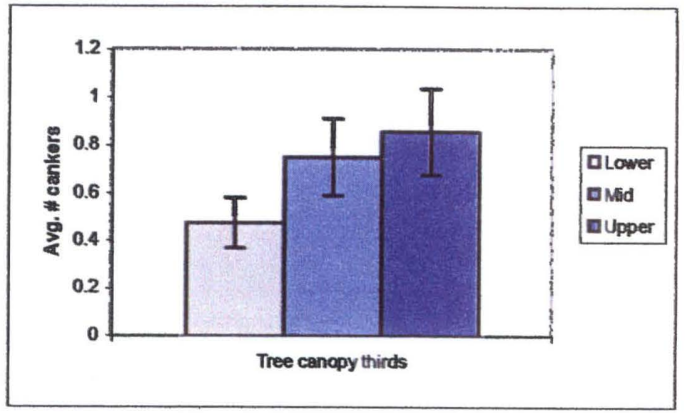

Figure 2. Average numbers of blister rust cankers in the lower, mid, and upper thirds of whitebark pine tree canopies. Error bars equal standard error.

An interesting trend was found in spatial associations between whitebark pine and Ribes montigenum (Fig. 3). There were six sites that supported significant amounts of Ribes montigenum, and of these, three showed that $R$. montigenum was located significantly $(\mathrm{p}<0.05)$ closer to a whitebark pine tree than to a random point. The two sites that clearly showed a non-significant association between whitebark pines and $R$. montigenum had high tree canopy cover estimations, showing a relatively closed, and thus sheltering, canopy. The fact that there is a positive correlation between whitebark pine and $R$. montigenum in exposed high-elevation sites suggests that there could be a facilitative association between the two host groups in these sites. It is intriguing to contemplate the long-term consequences, conceptualized in co-evolutionary concepts (Burdon and Thrall 1999), of the interaction between these pine and shrub species. The two species seem to have had a historic positive association prior to the interaction with this introduced fungal pathogen, which now may drive an indirect negative interaction. While it is interesting to give thought to such concepts, the possibilities for intensive study may be limited due to the time scales involved. 


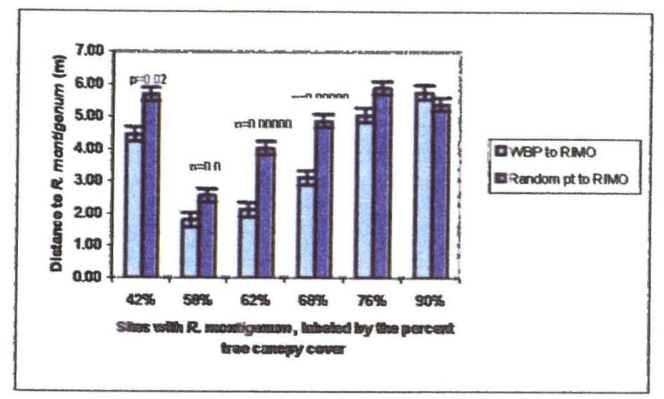

Figure 3. Spatial associations between whitebark pine trees and Ribes montigenum shrubs at six sites with differing estimated percent tree canopy cover. Error bars equal standard error.

\section{$\downarrow \quad$ FUTURE WORK}

This project will continue for another field season in 2002. The fact that no apparent trends between infection level and stand factors were apparent suggests that the selection of spatial scale was inappropriate. Because moderate-distance spore dispersal from Ribes to pines is possible, and may be more common than initially suspected, there are inherent challenges to sampling Ribes shrubs that potentially influence a particular whitebark pine stand. Data collection efforts in 2002 will focus on sampling Ribes and pine species composition and abundances across an elevation gradient to illustrate the amount of overlap between groups of host plants in a small number of sites with known high and low infection levels. In addition, data collection will occur at a smaller scale on Ribes shrubs to quantify within-shrub and within-patch patterns of infection. Different methodologies for sampling pathogen infection in Ribes shrubs will be developed, tested, and compared.

This field examination of white pine blister rust in the GYA is broadly aimed at contributing to our knowledge of the mechanisms involved in this complex disease system. It is recognized as being only one small step towards that challenging objective. While a quantitative description of realforest disease patterns needs to be considered with other on-going work at the molecular level and in controlled-environments to be truly valuable, it is necessary that the studies of the smaller parts of the system be set in the context of (and tested against) real-forest trends, documented in field studies such as this one.

\section{ACKNOWLEDGMENTS}

We gratefully acknowledge support for this project from the UW-NPS Research Station, the USFS Rocky Mountain Research Station, the American Wildlife Research Foundation, and the Sigma Xi Grants-in-Aid-of-Research Program. We are also grateful for valuable assistance provided by many individuals. Carol Brewer played an instrumental role in all phases of project development. Brian Geils provided ideas and plant pathology expertise. Daniel Tyers provided logistical support and shared his knowledge of local whitebark pine forests.

\section{$\uparrow$ Literature Cited}

Burdon, J.J. and Thrall, P.H. 1999. Spatial and temporal patterns in coevolving plant and pathogen associations. Am. Nat. 153 Supplement: S15-S33.

Campbell, E.M. and J.A. Antos. 2000. Distribution and severity of white pine blister rust and mountain pine beetle on whitebark pine in British Columbia. Can. J. For. Res. 30: 1051-1059.

Carlson, C.E. 1978. Noneffectiveness of Ribes eradication as a control of white pine blister rust in Yellowstone National Park. USDA Forest Service Northern Region Forest Insect and Disease Management, Report No. 78-18.

Catana, A.J. 1963. The wandering quarter method of estimating population density. Ecology 44: 349-360.

Despain, D.G. 1975. Field Key to the Flora of Yellowstone National Park. Yellowstone Library and Museum Association, Yellowstone National Park, 257 p.

Klinkowski, M. 1970. Catastrophic plant diseases. Ann. Rev. Phytopath. 8: 37-60.

Krebill, R.G. 1969. Study Plan for Cronartium ribicola: Effect of suboptimal temperature on germination of teliospores and infection of Pinus albicaulis. INT-2301-117. 
McCartney, H.A. 1994. Spore dispersal: environmental and biological factors. Pages 171-185 in J.P. Blakeman and B. Williamson, eds. Ecology of Plant Pathogens. $\mathrm{CAB}$ International, Wallingford, UK.

Maloy, O.C. 1997. White pine blister rust control in North America: A case history. Ann. Rev. Phytopath. 35: 87-109.

Mielke, J.L. 1943. White pine blister rust in western North America. Yale University School of Forestry Bulletin 52, 155 p.
Parker, K.R. 1979. Density estimation by variable area transect. J. Wildl. Manage. 43: 484492.

Smith, J.P. and Hoffman, J.T. 2001. Site and stand characteristics related to white pine blister rust in high-elevation forests of southern Idaho and western Wyoming. West. N. Am. Nat. 61: 409-416.

Weiner, J. 1995. On the practice of ecology. J Ecol. 83: 153-158. 